\title{
CONTROVERSIAS Y LITIGIOS EN TORNO AL USO DE LA PIEDRA EN JEREZ DE LA FRONTERA
}

\section{CONTROVERSIES AND DISPUTES ABOUT THE USE OF STONE IN JEREZ DE LA FRONTERA}

\author{
FERnANdo Aroca Vicenti \\ Grupo de investigación HUM726: Ciudad, Imagen y Patrimonio. España \\ viarfe37@gmail.com
}

\begin{abstract}
La piedra constituye el material por excelencia en las edificaciones y el paisaje urbano de Jerez de la Frontera. Su empleo no estuvo exento de conflictos con El Puerto de Santa María, propietaria de la mayoría de canteras de la Sierra de San Cristóbal, de donde se extraía principalmente el material utilizado para las obras. La cal y el yeso que producía Jerez actuaron en parte como moneda de cambio ante la presión de la vecina ciudad portuense.

Palabras claves: arquitectura; piedra; cantería; canteros; Jerez de la Frontera
\end{abstract}

The stone is the material par excellence in the buildings and the urban landscape of Jerez de la Frontera. His employment was not without conflict with El Puerto de Santa María, owner of the majority of quarries in the Sierra de San Cristóbal, where was extracted mainly from the material used for the works. Lime and plaster producing Jerez acted partly as a bargaining under the pressure of the neighboring city of El Puerto de Santa María.

Keywords: architecture, stone; masonry; masons; Jerez de la Frontera.

\section{INTRODUCCIÓN}

Conocida es la importancia de la piedra para la ciudad de Jerez de la Frontera, aunque su incidencia real en la arquitectura y el paisaje urbano aún no ha sido suficientemente tratada. Pese a su apreciable presencia en las edificaciones, la utilización de morteros o enjalbegados pueden hacer olvidar en muchos casos la composición de las mismas. A poco que se observen los edificios del casco histórico, desde los más monumentales a los más humildes -muchos de los cuales tras su deterioro permiten ver con más facilidad sus materiales-, se podrá constatar que, sin duda, Jerez es una ciudad donde predomina la piedra. Su auge 
constructivo ya desde el siglo $\mathrm{XV}$, con la renovación de antiguos templos, origina una amplia difusión de este material, de lo que da fe la presencia de un numeroso grupo de canteros jerezanos en la construcción de la catedral hispalense ${ }^{1}$. La expansión del tardogótico, acompañada de una notable presencia de maestros ${ }^{2}$, dio lugar a una verdadera eclosión de la cantería local que ha llegado de manera ininterrumpida hasta bien entrado el siglo XX.

La cercanía de canteras, tanto fuera como dentro del amplio término municipal jerezano, propició un constante uso de la piedra, cuyo transporte resultaba muy asequible, llegando a aventajar a otros materiales tradicionalmente considerados más económicos. Como es sabido, la mayor parte de la que se empleaba en Jerez provenía de las cercanas canteras de la Sierra de San Cristóbal, mientras que dentro del término fueron las de Martelilla y Gigonza las más explotadas, seguidas de algunas otras de menor entidad, enfocadas al abastecimiento de piezas muy concretas, como piedras para moliendas, empedrado urbano y algunas otras. Gran relevancia tuvieron también las extracciones para la fabricación de cal y yeso, materiales que, sin alcanzar la fama de los producidos en otros municipios - como fue el caso de Morón-, fueron muy demandados por importantes ciudades cercanas.

${ }^{1}$ La presencia de canteros jerezanos, tanto sacadores de piedra como oficiales, en la catedral sevillana ha sido ampliamente tratada por RODRÍGUEZ ESTÉVEZ, Juan Clemente: Cantera y obra. Las canteras de la sierra de san Cristóbal y la Catedral de Sevilla. El Puerto de Santa María, 1998, pp. 73-79; RODRÍGUEZ ESTÉVEZ, Juan Clemente: Los canteros de la Catedral de Sevilla. Del Gótico al Renacimiento. Sevilla, 1998; y RODRÍGUEZ ESTÉVEZ, Juan Clemente: "Los constructores de la Catedral", en La Catedral Gótica de Sevilla. Fundación y fábrica de la obra nueva. Sevilla, 2006, pp. 147-207.

${ }^{2}$ ROMERO MEDINA, Raúl y ROMERO BEJARANO, Manuel: "Un lugar llamado Jerez. El maestro Alonso Rodríguez y sus vínculos familiares y profesionales en el contexto de la arquitectura del tardogótico en Jerez de la Frontera”, en JIMÉNEZ MARTÍN, Alfonso (ed.): XVII Edición del Aula Hernán Ruiz 2010. La Catedral después de Carlín. Sevilla, 2010, pp. 175-274; ROMERO MEDINA, Raúl y ROMERO BEJARANO, Manuel: "Arquitectura tardogótica en el sur del antiguo Arzobispado de Sevilla: los maestros canteros y la construcción del puente de Cartuja (1525-1541)", Boletín del Museo e Instituto Camón Aznar, 10, 2010, pp. 251-288; ROMERO MEDINA, Raúl y ROMERO BEJARANO, Manuel: "La obra tardogótica de la Cartuja de la Defensión de Jerez de la Frontera. Reflexiones sobre la intervención de Diego de Riaño", De Arte, 16, 2017, pp. 3148; PINTO PUERTO, Francisco: Las esferas pétreas. Análisis de las soluciones del arte de la montera en la Provincia de Cádiz durante el Siglo XVI. Sevilla, 1998; ROMERO BEJARANO, Manuel: Maestros y obras de ascendencia portuguesa en el tardogótico de la Baja Andalucía. Tesis doctoral inédita, Universidad de Sevilla, 2014; y GUERRERO VEGA, José M.: Espacio y construcción en la arquitectura religiosa medieval de Jerez de la Frontera (s. XIII-XV). Tesis doctoral inédita, Universidad de Sevilla, 2016. 


\section{LA PIEDRA DE SAN CRISTÓBAL Y EL LITIGIO ENTRE DOS CIUDADES}

A medio camino entre Jerez y El Puerto de Santa María, la Sierra de San Cristóbal presenta un relieve de poca altura (cota máxima de $124 \mathrm{~m}$ ), formada por arenisca con cemento calcáreo (calcarenitas), cuya piedra se extraía ya desde el III milenio a.C. ${ }^{3}$. Aun tratándose de un material de cuestionable calidad, la riqueza de sus canteras propició una explotación continua, con una actividad a gran escala a partir del siglo XV a raíz de la construcción de la catedral de Sevilla, que empleó un alto porcentaje de ella ${ }^{4}$.

En la ciudad de Jerez esta piedra se manifiesta por cualquier zona de su casco histórico, bien a la vista o en muchos casos oculta tras enjalbegados, lo que explica en gran medida el ingente número de canteros que la utilizaron. Pero su extracción por parte de la ciudad no fue siempre fácil, pues la mayor parte de sus yacimientos se hallaban en el término municipal de El Puerto de Santa María, no faltando durante siglos reclamaciones de propiedad y libre disposición. Aunque fue en el siglo XVIII cuando se alcanzó la cima de las prohibiciones para el uso, estas se dieron desde siglos atrás ${ }^{5}$. Como propietario, el ayuntamiento portuense concedía las solicitudes de arrendamiento por seis meses, con la obligación por parte de los arrendatarios de entregar dos carretadas de cantos al semestre en el caso de que se realizasen obras públicas en la ciudad ${ }^{6}$.

En 1732 se decide impedir a Jerez la explotación de los yacimientos ante las considerables mermas de la piedra de mejor calidad ${ }^{7}$, coincidiendo con el levantamiento del primer templo de la ciudad, la nueva colegial, para lo que se envió una carta al cabildo portuense solicitando el libre uso. Este, anteponiendo la buena relación entre las dos ciudades, respondía que la causa de tan drástica determinación

${ }^{3}$ LÓPEZ AMADOR, Juan José; PÉREZ FERNÁNDEZ, Enrique y RUIZ GIL, José Antonio: "Historia y Arqueología en las canteras de El Puerto de Santa María", Revista de Arqueología, 124, 1991, pp. 36-46.

${ }^{4}$ RODRÍGUEZ ESTÉVEZ, Juan Clemente: Cantera y obra..., op. cit., pp. 43 y 54.

5 AMJF (Archivo Municipal de Jerez de la Frontera), Actas capitulares, año 1633, f. 1496. En este año el cantero jerezano Alonso de Pina se queja de los impedimentos de la ciudad de El Puerto para sacar la piedra libremente de las canteras. El Ayuntamiento jerezano acuerda enviar cartas a aquella ciudad, así como al duque de Medinaceli pidiendo "no se de motivo a questa ciudad siga pleito sobre la posesión inmemorial que tiene para poder sacar piedra de la canteras ynformandole de las causas y rrasones y previlegios que esta ciudad y sus vecinos tienen para ello".

${ }^{6}$ LÓPEZ AMADOR, Juan José; PÉREZ FERNÁNDEZ, Enrique y RUIZ GIL, José Antonio: "Historia y Arqueología...”, op. cit., p. 44.

7 Ibidem, pp. 44-45. El paulatino agotamiento de la piedra de mayor dureza dio lugar a excavaciones en mina en busca de nuevas vetas, con las consiguientes formaciones de cuevas. La primera explotación a cielo abierto se registra en 1758, aunque este sistema se desarrollará ampliamente a partir de principios del siglo XIX. 
era la escasez de piedra para nutrir a las numerosas obras locales, citándose como ejemplos la nueva fuente, hospicio de Misiones de Indias y convento de capuchinas, así como las obras de particulares ${ }^{8}$. Ante esta determinación Jerez traslada el caso a la Real Chancillería de Granada, alegando la tradicional disposición y conducción del material en carretas a la ciudad, en las más de doce canteras que acogían entre diez y doce operarios cada una, como asimismo su uso en todos los edificios de la ciudad, tanto antiguos como modernos, y la paralización de la nueva colegial, para cuyas obras iban destinadas varias cargas que se vaciaron, con la consiguiente desocupación de un gran número de canteros 9 . La audiencia granadina resolvió no impedir a Jerez las extracciones, aunque siempre bajo la licencia del cabildo portuense, de forma que la libre disposición quedaba bastante condicionada. En medio de este litigio y ante la preocupación por la paralización de las obras, el cabildo colegial decidió enviar a la ciudad vecina a un canónigo para que intercediese ${ }^{10}$, logrando que se restituyese el suministro a esta obra, mientras otras quedaban excluidas ${ }^{11}$.

La limitación del abasto se dejó sentir notablemente en Jerez mientras surgía una inflación en los precios de otros materiales, fundamentalmente ladrillo y cal, optándose por impedir su salida, como también la piedra de Martelilla y otras del término ${ }^{12}$. Con esta medida se intentaba paliar el vacío que la piedra de San Cristóbal dejaba en las obras, ya que solucionaba la firme y rápida ejecución de paramentos, portadas y cubiertas, cuya ausencia ocasionaría un mayor consumo de los otros materiales. Pero la medida adoptada era también una respuesta a la determinación portuense, una forma de presión de la ciudad, que gozaba de abundantes materiales en su amplio término municipal y abastecía a núcleos cercanos, entre ellos El Puerto de Santa María, sin intención de impedir el suministro destinado a obras públicas, como las murallas de Cádiz y otras de carácter oficial.

En el transcurso del litigio aparecen también algunas referencias a licencias para apertura de nuevas canteras por parte de jerezanos, como la concedida a Leonardo Fernández, en zona perteneciente al término de Jerez ${ }^{13}$, cuestión no definitivamente resuelta hasta época reciente. De cualquier forma debió tratarse de una explotación de piedra de menor calidad, ya que las mejores -de mayor dureza- se localizaban en los yacimientos de la jurisdicción portuense.

Las medidas de presión del cabildo jerezano ejercieron su efecto, provocando la permisividad de la ciudad vecina, como recoge la documentación a través de múltiples referencias al uso de la cantería en obras y nuevas construcciones. De

\footnotetext{
${ }^{8}$ AMJF, Actas capitulares, año 1732, ff. 221 y 231.

9 Ibidem, f. 331; y AMJF, leg. 150, expediente 4576.

${ }^{10}$ REPETTO BETES, José Luis: La obra del templo de la Colegial de Jerez de la Frontera. Cádiz, 1978, p. 391.

${ }_{11}$ AMJF, leg. 150, expediente 4576.

12 AMJF, Actas capitulares, año 1732, f. 421.

13 Ibidem, f. 304.
} 
esta forma las aguas volvieron a su cauce, de lo que da buena muestra la documentación, que no recoge nuevos impedimentos hasta cinco décadas más tarde.

En el año 1784 las reiteradas quejas por la escasez de piedra para las numerosas obras que se acometían en la ciudad llevó al síndico personero a realizar indagaciones al respecto, concluyendo que "era impedimento de la Ciudad del Puerto de Santa María en cuyo territorio se hallan las canteras". Se trataba de una nueva oposición similar a la anterior, por lo que se volvieron a activar los protocolos, con envíos de cartas al cabildo vecino, que en una primera respuesta se mantiene firme en la prohibición. Jerez alegaba, entre otras cuestiones, que no se había impedido el abastecimiento de cal, yeso, ladrillos e incluso piedra de Martelilla a aquella ciudad, motivo que puso freno a la prohibición de 1732, lo que corrobora la medida de presión a la que antes aludíamos ${ }^{14}$. En una nueva respuesta, José Bernabé y Madero, síndico portuense, manifiesta el desorden y libertad con que los canteros se habían excedido en la saca de materiales y su conducción a Jerez para sus obras públicas y particulares, con la consiguiente escasez para las locales, dando motivo para actuar a los diputados de campo. Alegaba también que no era nuevo este impedimento y el correspondiente control, con solicitudes de permisos como tantas veces había hecho "ese ylustre Ayuntamiento para la fabrica y templo del S. San Miguel de esa ciudad y la de Sevilla para la del Sagrario de aquella Santa Yglesia"15. Esto último pone de manifiesto la relativa libertad para el uso del material con sus autorizaciones, aunque cabe pensar que esta situación sería más frecuente en la demanda de la piedra de mejor calidad. Los dos edificios referidos, el jerezano de San Miguel y el Sagrario hispalense, hicieron uso de esta piedra, aunque el primero en mucha mayor medida -además de resto del templo, su torre fachada, a la que con toda probabilidad se refiere el documento, se levantó íntegramente en piedra de San Cristóbal, en el tercer tercio del siglo XVII-, mientras que en el segundo tuvo mayor protagonismo la piedra de Martelilla ${ }^{16}$. Esta medida desencadenó de nuevo un circunstancial desempleo de los canteros jerezanos allí establecidos, al quedar muchas obras interrumpidas por la falta del material ${ }^{17}$.

${ }_{14}$ AMJF, Actas capitulares, año 1784, ff. 159v y 160: "con la expresada razon se tuvo por reparable la determinacion que en otro tiempo tomo la ciudad del Puerto de impedir la extraccion de cantos de sus canteras".

15 Ibidem, f. 406.

${ }^{16}$ FALCÓN MÁRQUEZ, Teodoro: El Sagrario de la Catedral de Sevilla. Sevilla, 1977.

17 AMJF, Actas capitulares, año 1784, f. 265. Se habla de la interrupción de obras en la ciudad, con especial mención al cuartel del Tinte. Sobre los cuarteles en el contexto urbano del Jerez del XVIII y en especial el del Tinte, de caballería, vid. AROCA VICENTI, Fernando: "Sobre arquitectura pública durante el siglo XVIII en Jerez", en I Jornadas de Historia del Arte en Jerez de la Frontera. Arquitectura y diseño de la ciudad desde el siglo XVI hasta Isabel II. Jerez, 2014, pp. 116-124. 
El nuevo recurso interpuesto por Jerez ofrece interesante información, a través de una serie de puntos, entre los que destacan el libre uso de las canteras desde el año 32 hasta la fecha (1784), como también la inexistencia en Jerez de yacimientos de piedra franca para las construcciones; igualmente el excesivo número de las de El Puerto, capaces de abastecer tanto a la demanda local como a la de las localidades próximas; asimismo la difusión del ladrillo como material sustitutivo, aunque "sumamente costoso y no capas de poder suplir su falta por la excases de su fabrica y no correr esta en tiempo de invierno" "18. En este informe testificaron Juan Díaz, maestro mayor de obras de la ciudad, el maestro de albañilería Agustín Crespo y el alarife José de Vargas.

La ciudad de El Puerto vuelve a reanudar su condición de legítima propietaria, obligando a solicitar licencias para las explotaciones, a la vez que incidía nuevamente en las necesidades de cubrir sus propias obras, como "el aqueducto de las aguas de Sidueña de orden de nuestro Consejo de Castilla", el hospicio de las Misiones de Indias, convento de capuchinas o las futuras casas consistoriales, cárcel, pósito y muelle en el río. Manifiesta también el agotamiento de las minas, cuyo esquilmado en busca de las vetas de mejor calidad provocó el hundimiento de una de ellas $^{19}$. Finalmente se reafirma en la libertad de conceder las licencias, sin negar a Jerez los permisos, aunque prevaleciendo siempre la prioridad de las obras locales.

Ante estas circunstancias el cabildo jerezano vuelve a establecer un férreo control en los materiales de fabricación propia, principalmente cal y yeso, así como la piedra de Martelilla y Gigonza. El aumento de sus precios volvía a ser objeto de atención por parte de las autoridades, firmes en la decisión de impedir la extracción de estos productos sin el conocimiento del síndico personero y la expresa licencia del corregidor. La abundancia de piedra para la fabricación de cal y yeso, así como de la vegetación necesaria para alimentar los hornos para su cocción, repartidas por el amplísimo término municipal, solucionaban la tradicional demanda de las localidades cercanas, por lo que fue en este asunto donde más se incidió ${ }^{20}$.

Pese a los continuos litigios y la aceptada propiedad portuense de la mayor parte de las canteras, la demarcación de los límites entre las dos ciudades era largamente debatida, hasta llegar a la actualidad. Sirvan como ejemplo algunas referencias al respecto plasmadas en los acuerdos capitulares, como en 1786 en que se acuerda elevar ante los tribunales la demarcación de límites a raíz de haberse despojado a Jerez de una cantera, aunque de mala calidad y escasa producción. Del mismo modo en 1796 se vuelve a plantear el establecimiento de la mojonera divisoria entre los dos municipios ${ }^{21}$.

18 AMJF, leg. 150, expediente 4575, año 1784, s. f.

${ }_{19}$ Ibidem. En el hundimiento se habla de tres muertes.

20 AMJF, Actas capitulares, año 1784, doc. 96; y AMJF, leg. 150, expediente 4576, año 1784

${ }^{21}$ AMJF, Actas capitulares, año 1786 f. 60v, y año 1796, f. 416. 
Durante el siglo XIX la actividad por parte de los canteros jerezanos continuaba en plena efervescencia, con el dilatado debate de la demarcación de términos. Así, en 1862 se registra un pleito entre dos canteros por una explotación -algo frecuente desde siglos atrás-, con el abandono de una mina por parte de Juan Campos tras su explotación durante una serie de años, siendo ocupada por José Manzanero, que justificaba una inversión de más de seis mil reales en ella. El intento de reutilizarla por parte del primero llevó a la intervención de las autoridades jerezanas, dado la supuesta ubicación en su jurisdicción. Pero el verdadero interés de este caso reside en la mención al reglamento vigente de canteras, con referencia expresa al artículo quinto: "Podra cada cantero inteligente tener establecida dos canteras de distintas clases, por la diferencia de materiales que se necesitan extraer, entendiéndose que esta medida tiene por objeto el fomento de la industria de los trabajadores, pero con la prevención que el cantero que debe trabajar en ellas no tendra derecho de seguir labrando si dejase pasar el termino de un año sin escavarlas ni estraer materiales, pudiéndose poner otro individuo a trabajar en ellas sin disputa". La comisión de Policía Rural acordó acudir a la cantera con el arquitecto titular y cuatro expertos en la materia, que también explotaban otras en la misma zona -una muestra más de la actividad de los operarios jerezanos en la Sierra de San Cristóbal-, determinando la vuelta del mencionado José Manzanero a la mina, aunque debiendo seguir una extracción en dirección frontal para evitar el encuentro con otra excavación. De cualquier manera la cuestión no quedaba del todo aclarada, pues la propia comisión añade que "no esta aun terminado el deslinde del termino de esta ciudad y el Puerto de Santa Maria"22.

Estos frecuentes litigios plantearon la necesidad de un reglamento propio, ya que el mencionado artículo quinto correspondía al elaborado por la ciudad de El Puerto, habitualmente aplicado a todas las explotaciones. De esta forma, en 1863 se elabora un reglamento para las canteras que "son exclusivamente las que se encuentran radicadas y conocidas dentro del termino de esta ciudad y no las que están en cuestión con el Puerto de Santa María”, con envío el 18 de diciembre al gobernador civil de la provincia de Cádiz para su aprobación ${ }^{23}$. El proyecto abordaba a través de veinticinco artículos una serie de cuestiones, como la distancia para labrar en las canteras antiguas, o el permiso para tener dos canteras de distinta clase con la condición de que si se abandonasen por espacio de un año no se podría retomar el uso. Especial atención se dispensaba al sistema de cuevas surgidas por la extracción desde siglos atrás, por lo que se obligaba a mantener las arquerías con pilares, sancionándose a quienes los picaran para obtener material; también se prohibía abrir lumbreras a no ser que se formase un cercado a sus alrededores, no permitiéndose trabajar sin luz del día. El control de las explotaciones

\footnotetext{
22 AMJF, leg. 150, expediente 4587, año 1862, s. f.

${ }^{23}$ Ibidem, expediente 4588, año 1863.
} 
se haría en un libro donde habrían de inscribirse los canteros con los correspondientes permisos otorgados por el ayuntamiento y acreditación de experiencia en el oficio, inspeccionándose cada quince días todas las minas por la autoridad competente, como asimismo dos reconocimientos anuales por la comisión de Policía Rural. El gobierno provincial acordó aprobar el reglamento presentado, pero conminando a que sobre el aprovechamiento común se recordase el artículo $3^{\circ}$ de la Ley de Minas de 1859, donde se establecía la vigilancia de la Administración en el uso de los minerales con aplicación a la construcción, agricultura o las artes. Igualmente que los controles y reconocimientos ejercidos por el municipio habrían de estar siempre subordinados a la dirección facultativa del cuerpo de ingenieros del ramo. Mientras se alternaban reglamentos y disposiciones legislativas, y ante la falta de acuerdo en los límites de términos, los canteros jerezanos continuaban explotando las minas dado la demanda del gran crecimiento urbano propiciado por la industria del vino. Sirva como ejemplo la petición en 1872 de Antonio López Galindo para trabajar la cantera llamada La Esperanza, situada "en el terreno de la Sierra de San Cristobal que litigan esta ciudad y la del Puerto de Santa María"24.

La piedra de San Cristóbal está presente en la mayor parte de los trabajos de cantería desarrollados en la ciudad, y aunque sus cualidades la hacen poco propicia para el tallado ornamental -por ser fácilmente degradable debido a su composición-, no faltaron hábiles maestros capaces de extraerle las máximas posibilidades (Figura 1).

\section{LA PIEDRA DE MARTELILLA, GIGONZA Y OTRAS}

Pese a las reiteradas afirmaciones a la inexistencia de piedra franca en la ciudad, expuestas como argumento en los litigios con El Puerto, existían canteras propias que desde siglos atrás suministraban piedra no solo a Jerez sino también a otros núcleos cercanos. Es evidente que la demanda de la de San Cristóbal superaba ampliamente a las otras, considerándose como base para las construcciones. Dentro del término jerezano las más importantes eran las situadas en la dehesa de Martelilla, a unos 13 kilómetros del casco urbano en dirección a Medina Sidonia, cuya explotación, a cielo abierto, se inició a raíz de la construcción del puente de Cartuja (1525-1541), que exigía una piedra más compacta y resistente al agua que la de San Cristóbal ${ }^{25}$. Esta piedra caliza de grano fino $^{26}$, pese a no ser de una

${ }^{24}$ AMJF, leg. 150, expediente 4587, año 1872.

${ }^{25}$ ROMERO MEDINA, Raúl y ROMERO BEJARANO, Manuel: "Arquitectura tardogótica en el sur...”, op. cit. Este puente sobre el Guadalete está a unos seis kilómetros del casco urbano.

${ }^{26}$ VILLEGAS SÁNCHEZ, Rosario; ARROYO TORRALBO, Fátima; RODRÍGUEZ SANCHÍS, Jorge y MORENO PASCULVACA, Sandra: "La alteración de la 
gran calidad, resultaba más idónea que la portuense para elementos más resistentes, como gradas, escaleras o solerías, así como la talla ornamental y labores escultóricas, lo que facilitó su difusión y demanda para obras de gran envergadura, como la catedral o las casas capitulares de $\mathrm{Sevilla}^{27}$. Como propietaria de las canteras, la ciudad exigía permiso para su explotación, llevada a cabo normalmente por canteros locales, aunque en algunos casos la saca por foráneos originó algunas reivindicaciones. Así ocurrió en 1538 cuando, tras la pertinente licencia, se enviaron a Sevilla para la obra de la catedral 1.200 carretadas de piedra y la misma cantidad al año siguiente, todo ello extraído por canteros de aquella ciudad. La reacción de los operarios jerezanos no se hizo esperar, elevando sus quejas al cabildo mientras expresaban que "a sacado la dicha piedra con canteros de la dicha cibdad de sevilla traydos de ella lo qual a sido en prejuyzio nuestro [...] pues en esta cibdad ay oficiales que lo saben hazer y dar recaudo de todo lo que se les demandare y emos gastado nuestro trabajo en desabrir las dichas pedreras suplicamos a V S que no se permita ny de lugar que de aquí adelante ninguna persona estrangera que no sea vezino pueda sacar piedra de la dicha pedrera". Este hecho no debió ser muy frecuente, pues continúan expresando que "sevilla lo ha guardado continuamente de toda la canteria que a llevado a la iglesia mayor y para otras partes enbiando a conprar de los oficiales y ansy estamos nosotros prestos de sacarsela"28. También en 1538 se recoge una solicitud para la obra del nuevo ayuntamiento sevillano de "buena cantidad de carretadas desta piedra [...] que no sea tan a menudo importunado de nuestra parte" 29 .

Pese a las condiciones de sus canteras - no equiparable a la riqueza de las de San Cristóbal-, la piedra de Martelilla se distribuía entre algunas obras de la ciudad y otras del entorno, consolidándose como material idóneo para portadas y zonas destinadas a la ornamentación. Aparece así durante el siglo XVI en edificios como el ya mencionado puente de Cartuja, las casas capitulares o los palacios de Riquelme y Ponce de León, cuyos programas decorativos lograron un alto grado de refinamiento. En la siguiente centuria la portada de la iglesia del monasterio de la Cartuja es buena muestra de ello. También en Sevilla, además de las obras ya mencionadas, está presente en el Sagrario de la catedral o el palacio

piedra en la Catedral de Jerez de la Frontera (Cádiz, España)”, en PEINADOS HERREROS, María de los Ángeles (coord.): I Congreso Internacional "El patrimonio cultural y natural como motor de desarrollo: investigación e innovación”. Sevilla, 2012, pp. 693-701.

${ }^{27}$ RODRÍGUEZ ESTÉVEZ, Juan Clemente: Los canteros..., op. cit., p. 132. Esta piedra inició su presencia en la catedral en 1538, siendo más habitual en la segunda mitad de siglo. Su uso en las casas capitulares en MORALES MARTÍNEZ, Alfredo J.: La obra renacentista del Ayuntamiento de Sevilla. Sevilla, 1981.

${ }_{28}$ AMJF, Actas capitulares, año 1539, f. 584v.

${ }_{29}$ Ibidem, f. 611. No se especifica la cantidad del material. 
Arzobispal, como obras más relevantes, como también en la parroquia de Santa María de la Mesa de Utrera $^{30}$.

Dentro sus limitaciones productivas, estas canteras mantuvieron durante el siglo XVIII una destacada actividad, con dos principales zonas a las que continuamente alude la documentación: el Cerro del Viento y de la Cueva, y el Cerro del Toril y de la Mesa, de donde se extraían también piedras para la fabricación de yeso y cal. Su explotación, bajo control municipal, se realizaba generalmente por períodos semestrales o anuales prorrogables, aunque en algunos casos la inexistencia de permiso propició las denuncias de otros usuarios. Tampoco faltaron los litigios entre canteros por invasiones de minas en uso, cuyos expedientes arrojan interesantes datos, como los mencionados nombres de las canteras o régimen de explotación, que podía incluir la aparcería. Fue este el caso de Antonio Zarzana, quien denuncia a Pedro Arriaño por introducirse en su mina. En el expediente incoado al efecto aparece el arquitecto Juan de Vargas como aparcero de la explotación ${ }^{31}$, hecho que evidencia la vinculación de los maestros de obra con el ámbito empresarial en torno a la construcción. Igualmente se resalta el derecho a la explotación de la cantera: "si un vecino tiene abierta alguna cantera [...] y mientras no quiera dexarla porque siendo costoso y gravoso el descubrirlas y escombrarlas para ponerlas usuales y corrientes, este trabajo y dispendio costoso le dara privilegio y antelación a otro cualquiera pues de lo contrario se daría el caso de que echandose sangre trabajo y caudal algún vecino en descubrir

${ }^{30}$ FALCÓN MÁRQUEZ, Teodoro: El Sagrario..., op. cit., p. 45; SANCHO CORBACHO, Antonio: Arquitectura barroca sevillana del siglo XVIII. Madrid, 1984, p. 124; y HERRERA GARCÍA, Francisco J.: "Lorenzo Fernández de Iglesias, un maestro cantero montañés en Andalucía occidental”, Atrio, 0, 1988, p. 15. En 1618 el maestro albañil utrerano Pedro Gutiérrez, estante en Jerez, recibe una partida de piedra de Martelilla para la iglesia de Santa María de la Mesa de aquella localidad. JÁCOME GONZÁLEZ, José y ANTÓN PORTILLO, Jesús: "Apuntes histórico-artísticos de Jerez de la Frontera en los siglos XVI-XVIII ( $2^{\mathrm{a}}$ serie)", Revista de Historia de Jerez, 7, 2002, p. 106.

${ }^{31}$ AMJF., leg. 150, expediente 4572, año 1763, ff. 1-26. Al fallecer el titular Antonio Zarzana, su mujer le da poder para que la representara en el caso: "Juan de Bargas vecino desta Ciudad y Maestro Mayor de obras en ella [...] dijo [...] yo soy aparcero con compañía establesida en una cantera al sitio de Martelilla". Juan de Vargas fue un destacado arquitecto de la segunda mitad del setecientos jerezano. Sus obras, tanto religiosas como civiles, acusan un acentuado dinamismo, con pleno dominio de la piedra, como demuestra en la portada del palacio Bertemati, o las espadañas de San Marcos y Santiago. MORENO ARANA, José Manuel: "Notas documentales para la Historia del Arte del siglo XVIII en Jerez", Revista de Historia de Jerez, 9, 2003, pp. 95-101: ÁLVAREZ LUNA, María de los Ángeles; AROCA VICENTI, Fernando; GUERRERO VEGA, José María y ROMERO BEJARANO, Manuel: "Historia de la Casa Bertemati”, en PINTO PUERTO, Francisco (coord.): La Casa Palacio Bertemati (1776-2006). Córdoba, 2008, pp. 25-67; y AROCA VICENTI, Fernando: Arquitectura y urbanismo en el Jerez del siglo XVIII. Jerez, 2002, pp. 215-216. 
sitio oportuno para la fabrica y saca de la piedra asi la tubiese corriente y aun sin aver usufructuado cosa alguna en perjuisio de esto vendría otro vecino a su disfrute". Los casos de explotación sin licencia fueron celosamente controlados, y en sus procesos eran frecuentes las declaraciones de testigos, como ocurrió en la denuncia de Francisco de Arriaño contra Nicolás de Arenas por "haver abierto cantera en sitio baldio sin tener licencia”. En esta ocasión se presentaron por testigos otros dos sacadores, Juan y Diego Centeno, quienes atestiguan la intromisión del acusado en la cantera "sin guardar la distancia de cien pasos", así como la venta del material a localidades de la comarca sin autorización ${ }^{32}$. El caso se resolvió con la presencia in situ del alguacil de vagabundos -acompañado de un ministro de justicia, dos soldados del Real Cuerpo de Artillería y un escribano-, quien procedió al embargo de los bienes del acusado y su traslado a la cárcel de la ciudad ${ }^{33}$.

Pese a su cuestionable calidad, la piedra de Martelilla seguía siendo demandada para importantes obras tanto dentro como fuera de la ciudad. Entre las numerosas solicitudes que figuran en la documentación, podemos destacar la enviada en 1786 por don Ignacio Imperial Diquery, ingeniero en jefe de Marina y director de las Reales Obras de la Nueva Población de San Carlos, en la Isla de León, quien ajusta con Juan García Quintanilla y Jacinto Gener su proveimiento "por ser la mas conveniente para el mejor servicio del Rey en estas Reales Obras de la Nueva Población de san Carlos de mi cargo". Estos últimos, vecinos de la Isla de León y "asentistas de las Reales fabricas de iglesia y otras oficinas que se construyen en la nueva población de san Carlos", solicitan la saca de piedra del Cerro del Toril y de la Mesa, como asimismo la construcción de hornos de cal en el lugar, con el esparcimiento y pasto del ganado empleado en la conducción del material hasta su destino ${ }^{34}$. En la misma Isla de León la piedra de Martelilla fue también empleada, junto a otras tantas, en las obras del nuevo Real Observatorio Astronómico ${ }^{35}$.

${ }^{32}$ AMJF, leg. 150, expediente 4574, año 1783, f. 3: "y sabe el testigo que dicho Arenas faltado a la prohibición lleva piedra de martelilla para vender a los pueblos de la comarca como es la Ysla, Cadiz, Puerto Real y Puerto de Santa Maria".

${ }^{33}$ Ibidem, f. 4v. El alguacil salió de la ciudad a las diez de la mañana, llegando a la cantera del Cerro del Viento sobre las doce del mediodía. En el embargo de sus bienes figuran "una barra grande de hierro, una Asada encabada un Amartilla una Almaina un hierro un mazo una escuadra una espiocha, ocho cuñas de hierro y barias porciones de piedra labrada y por labrar". Posteriormente, y por mediación del denunciante, se archiva la causa y Arenas queda en libertad, aunque pronto vuelve a ser denunciado de nuevo por el mismo Arriaño y semejantes motivos.

${ }^{34}$ AMJF, leg. 150, expediente 4579, año 1786, s. f. Dada la importancia de las obras, de carácter real, se conceden todas las licencias solicitadas.

${ }^{35}$ MARTÍNEZ MONTIEL, Luis F.: El Real Observatorio Astronómico de San Fernando (1769-1869). Sevilla, 1989, p. 140. 
En Jerez se hace patente en algunas partes de la catedral, portada principal del sagrario de la parroquia de San Miguel, portada del convento de San Francisco, portadas de los palacios de Bertemati (Figura 2) y Campo Real, entre otros edificios, incluyéndose, como hemos señalado, en solerías, gradas o escaleras de otros muchos.

Piedra de gran uso fue también la procedente de Gigonza, antiguo despoblado -con restos de un castillo- que actualmente se inscribe en el término municipal de San José del Valle (antes pedanía de Jerez, independizada en 1995), así como la de Tempul, perteneciente al término municipal, aunque ya hoy compartido con las localidades de San José del Valle, Arcos de la Frontera y Algar. De ambas zonas -aunque en mayor medida de Gigonza- se extraía una piedra caliza de gran dureza y compacidad, de color blanco o grisáceo, idónea para elaborar estructuras específicas, fundamentalmente pilares, escalones, gradas y piedras de molinos. Existe constancia documental de su uso desde el siglo $\mathrm{XVI}^{36}$, con gran demanda durante el XVII ${ }^{37}$. La intensa actividad constructiva desarrollada en la ciudad durante el setecientos encontró en la piedra de Gigonza un material idóneo para algunos elementos en edificios de carácter más funcional-como almacenes, bodegas o graneros-, fundamentalmente pilares con fustes de una sola pieza. También aparece en obras más relevantes como la Alhóndiga y Panadería, en la plaza del Arenal, tanto en los interiores como en los pilares de los soportales de sus fachadas ${ }^{38}$ (Figura 3). Por su dureza y cohesión abunda en las esquinas de las fachadas de edificios, para atenuar el impacto del tráfico rodado.

Hasta el momento, los escasos estudios y referencias a las canteras jerezanas no han reparado en el gran desarrollo que tuvo en ellas la fabricación de cal y yeso. Hemos comprobado cómo la demanda de estos materiales actuó como moneda de cambio para la libertad de uso de la portuense piedra de San Cristóbal. Mucho más que la piedra franca fue solicitada la caliza para fabricar cal y yeso, tanto en obras locales como foráneas, como se recoge ya desde finales del XVII, donde algunas entidades religiosas demandan construir hornos de cal para las obras de sus iglesias ${ }^{39}$. Del mismo modo hubo peticiones desde Cádiz para las

${ }^{36}$ Sirva la solicitud en 1516 de un picapedrero para sacar piedra de Tempul para "hazer piedras de atahona y para hazer piedras para el hazeyte". AMJF, Actas capitulares, año 1516 , f. 550v.

${ }^{37}$ La abundante documentación indica la demanda de esta piedra de Tempul y Gigonza sobre todo para molinos y atahonas, tanto por locales como foráneos. AMJF, Actas capitulares, año 1655, f. 22; año 1661, f. 50, y año 1662, f. 989. También durante el XVIII se registran numerosas solicitudes. Como simple muestra: AMJF, Actas capitulares, año 1702, f. 636, y año 1788, f. 162.

${ }^{38}$ Estos edificios fueron objeto de una intensa reforma a raíz del incendio ocurrido en 1794. Entre los nuevos elementos ejecutados se señalan trece pilares de piedra de Gigonza. AROCA VICENTI, Fernando: "Sobre arquitectura pública...", op. cit., pp. 127-128.

${ }^{39}$ Así lo hace el convento de Belén en 1677, la hermandad de la Caridad en 1686 o la Compañía de Jesús en 1693, las dos últimas en el llamado Hato de la Carne. AMJF, Actas capitulares, año 1677, f. 33, año 1687, f. 55 v, y año 1693, f. 148. 
obras de la iglesia del Rosario, así como las murallas ${ }^{40}$. Durante el XVIII se intensifica esta demanda, normalmente atendida por los fabricantes jerezanos, con un gran movimiento en la producción y transporte a diferentes poblaciones como Cádiz, El Puerto de Santa María, San Fernando o Sevilla ${ }^{41}$. La documentación también especifica a veces las obras de destino, como el Puerto Piojo de Cádiz ${ }^{42}$, o un conjunto tan significativo para la arquitectura española de la Ilustración como el Real Arsenal de la Carraca en San Fernando ${ }^{43}$. Toda esta actividad continuó durante el siglo XIX, coincidiendo con el auge constructivo de la ciudad, que crecía a un acelerado ritmo gracias a la industria del vino, cuyas bodegas se diseminaban por todo el ámbito urbano ${ }^{44}$.

Los ejemplos citados constituyen solo una pequeña muestra del gran desarrollo que adquirió en Jerez el comercio de cal y yeso, extraídos de su extenso término municipal, con abundante madera para la cocción de sus bosques y dehesas. La difusión de los hornos propició un edicto del corregidor en 18 de mayo de 1768 para el control de los erigidos sin licencia, que privaba al cabildo de sus rentas e impuestos, una parte destinada a la reedificación de los muros del alcázar ${ }^{45}$. Asimismo para la regulación de las medidas -como también del ladrillo y teja-, se encomienda a los maestros alarifes Juan Díaz, Antonio Palacios y Juan de Vargas

40 AMJF, Actas capitulares, año 1694, f. 736v: Juan Moreno, cura de la iglesia del Rosario, pide licencia para extraer piedra de yeso para sus obras. AMJF, Actas capitulares, año 1697, f. 75v: Francisco Lozano Alcaraz, vecino de Cádiz, pide licencia para hacer hornos de cal "en el sitio de prado redondo que confina con Martelilla [...] para las obras de las murallas de la ziudad de cadiz". La Ciudad concede la licencia.

${ }^{41}$ AMJF, leg. 150, expediente 4577, año 1784, s. f.: se concede licencia a Antonio Rosellón, patrón del barco "La Virgen del Carmen”, de El Puerto, para sacar por el río 4.000 quintales de yeso. También a Domingo Martín y Juan y Diego Boadas, de Jerez, para cargar tres falúas de su propiedad con 100 quintales de yeso destinadas a Cádiz. Igualmente a Francisco de Celis, jerezano fabricante de yeso, para enviar a Sevilla cuatro embarcaciones con 200 quintales cada una de dicho material.

42 AMJF, leg. 150, expediente 4577, año 1784, s. f. El 21 de agosto del mismo año se concede licencia a José Huertas, vecino de Cádiz y residente en Jerez, para sacar por el río 1.500 quintales de yeso para las obras del Puerto Piojo. Asimismo a José Villegas, jerezano fabricante de cal, llevar por el río hasta Cádiz 30 cahíces de cal de los 200 que tenía contratados, en fecha 23 de agosto del mismo año para las mismas obras.

${ }_{43}$ AMJF, leg. 150, expediente 4577, año 1784: el 30 de agosto se concede licencia a Diego Benítez para sacar de Jerez y llevar por el río para la obras de los Reales Arsenales 1.000 quintales de yeso. AMJF, leg. 150, expediente 4579, año 1792: se concede licencia a Manuel Gutiérrez, de Jerez, para sacar piedra en el baldío de la Gradera para proveer las obras de la Carraca. Sobre el Arsenal de la Carraca, vid. BARROS CANEDA, José Ramón: Arquitectura y Urbanismo en la Carraca durante el siglo XVIII. Sevilla, 1989.

44 AROCA VICENTI, Fernando: De la Ciudad de Dios a la Ciudad de Baco. La arquitectura y urbanismo del vino de Jerez (siglos XVIII-XX). Jerez, 2007.

${ }^{45}$ AMJF, sección Histórico Reservado, cajón 6, n. 30, f. 385. 
un reglamento en 1782 , donde se establecía para la cal el cahíz y la carga: "y se compone cada una de ellas de tres fanegas raidas y por carretada sesenta y tres espuertas de tres hojas de empleita de la mas ancha [...] debe tener cada una fanega cuatro pies cubicos y trescientas ochenta y ocho purgadas cubicas por la vara castellana y prevenimos debe estar dicha medida forrada con chapas de fierro", mientras el yeso habría de venderse por quintales. Muy indicativa resulta la observación que se hace sobre la piedra franca: "en quanto a las calidades y tamaños de la piedras francas de que usamos, omitimos especificarlas por no ser las canteras de esta ciudad y venir de otro término las que aquí se gastan", lo que corrobora la difusión de la piedra de San Cristóbal en detrimento de la de Martelilla. También se indica que ningún arriero ni otra persona puedan transportar cantos que no sean duros y de regulares tamaños, siendo condenados a la devolución de su importe en caso de incumplimiento de las normativas ${ }^{46}$.

La valoración de la piedra en Jerez queda avalada por su aplicación a todo tipo de inmuebles, tanto religiosos como civiles. En la nueva obra de la colegial -hoy catedral-, se desató un conflicto al erigirse las bóvedas de sus naves laterales en ladri1lo, cosa que no gustó a su cabildo, que consigue recuperar la piedra para la nave mayor $^{47}$. La polémica traspasó el ámbito eclesiástico hasta llegar al cabildo municipal, encargado de suministrar los medios económicos derivados del arbitrio de las dehesas, así como de los ocho reales del impuesto por cada bota de vino que salía de la ciudad, destinados mediante facultad real para la obra. El marqués de Casa Pavón, veinticuatro, llegó a proponer el desmonte de estas bóvedas para rehacerlas de cantería, justificando su imperfección frente al resto de la obra pétrea, a la vez que alababa los antiguos templos de la ciudad: "y mas en una ciudad en que ninguna de sus parroquiales tienen bovedas de ladrillo cuios templos son tan magnificos que pueden ser Colegiales siendo obra tan Corta" ${ }^{48}$. Esta pretensión se avalaba con un informe de Juan de Pina, autor de las bóvedas de la nave central, que justificaba las ventajas de la piedra sobre el ladrillo para las bóvedas y presupuestar así la

${ }^{46}$ AMJF, leg. 270, expediente 8217, año 1783. El reglamento se redactó en 1782 aunque no se hizo efectivo hasta el año siguiente.

${ }^{47}$ Las naves colaterales fueron trazadas por los hermanos Diego Antonio e Ignacio Díaz. Este último sustituyó a su hermano, maestro mayor del arzobispado, en la dirección de las obras del nuevo templo en 1724 hasta 1749 en que le sucede Juan de Pina. La falta de conocimientos de ambos en el arte de la cantería propició el trazado de las bóvedas en ladrillo, tras apelar a las autoridades eclesiásticas sevillanas para que convencieran a los canónigos jerezanos de que sería la mejor opción. Para la nave principal, como en el resto del templo, se recuperó la piedra de la mano del arquitecto jerezano Juan de Pina, experto en el oficio de la cantería. REPETTO BETES, José Luis: La obra del templo..., op. cit., pp. 185,381 y 399 .

48 AMJF, Actas capitulares, año 1753, f. 425. 
cantidad de 810 carretadas necesarias para este cometido ${ }^{49}$. Por el contrario, el también veinticuatro Pedro de Mendoza Ponce de León veía descabellado el desmonte de las bóvedas, sosteniendo la efectividad del ladrillo frente a la porosidad de la piedra de San Cristóbal y apelando en todo caso al uso de la más consistente de Martelilla ${ }^{50}$. Finalmente, y para enmascarar el ladrillo las bóvedas colaterales, fueron "sacadas a plana" y pintadas de cantería fingida ${ }^{51}$, tal y como actualmente permanecen, unificando así la imagen del conjunto pétreo (Figura 4).

A través de estas páginas hemos pretendido realizar una aproximación al uso de la piedra en la ciudad de Jerez de la Frontera, a través de sus controversias y litigios, algo que es necesario considerar al abordar el proceso evolutivo de su arquitectura y urbanismo. La historiografía tradicional, que ha visto siempre en Jerez una incondicional adopción de los modelos sevillanos, no prestó la suficiente atención a este material como elemento determinante en los caracteres formales de las obras. Como ejemplo, a poco que se observe la arquitectura barroca se advertirán algunas notas diferenciales, consecuencia en buena medida del material utilizado. Mientras que en Sevilla se trabajaba básicamente la albañilería, Jerez se aferraba a la cantería, con especial incidencia en el levantamiento de fachadas, portadas, torres y espadañas. Un buen número de estas últimas fueron erigidas a lo largo del setecientos, casi todas en piedra ${ }^{52}$ (Figura 5), con una clara adecuación de las formas al material, pues se apartan considerablemente de los modelos sevillanos de ladrillo con frecuente decoración de azulejos, muy difundidos por otros núcleos de su antigua diócesis.

Resulta necesario, a través de futuros trabajos, profundizar en todos estos factores que propiciaron en Jerez un acentuado gusto hacia la piedra, cuyas sólidas bases quedaron establecidas con el levantamiento y renovación de los templos tardogóticos, que tanta admiración despertó entre los jerezanos de las Edades Moderna y Contemporánea. Quizás las frecuentes miradas a las formas del último gótico, reflejadas en algunas obras de los siglos XVII y XVIII, encuentren cierta justificación en esa predilección por la cantería.

Fecha de recepción: 30 de octubre de 2018

Fecha de aceptación: 5 de febrero de 2019

49 Ibidem, f. 424. Pina habla de la porosidad tanto de la piedra como del ladrillo, así como las ventajas y perdurabilidad de las bóvedas de cantería.

50 AMFJ, Actas capitulares, año 1754, f. 399: "teniendo la piedra franca de nuestras canteras menos solidez sin comparación que el ladrillo [...] siendo mas porosa vemos por la experiencia recibe con mas facilidad las impresiones salinitrosas del ambiente [...] por lo que solamente se puede asentir a dicho dicatmen haciéndose dichas vobedas de la piedra martelilla de que estan fabricadas las portadas y cuatro pilares del crucero".

${ }^{51}$ REPETTO BETES, José Luis: La obra del templo..., op. cit., p. 405.

52 AROCA VICENTI, Fernando: Arquitectura y urbanismo..., op. cit., pp. 215-219. 


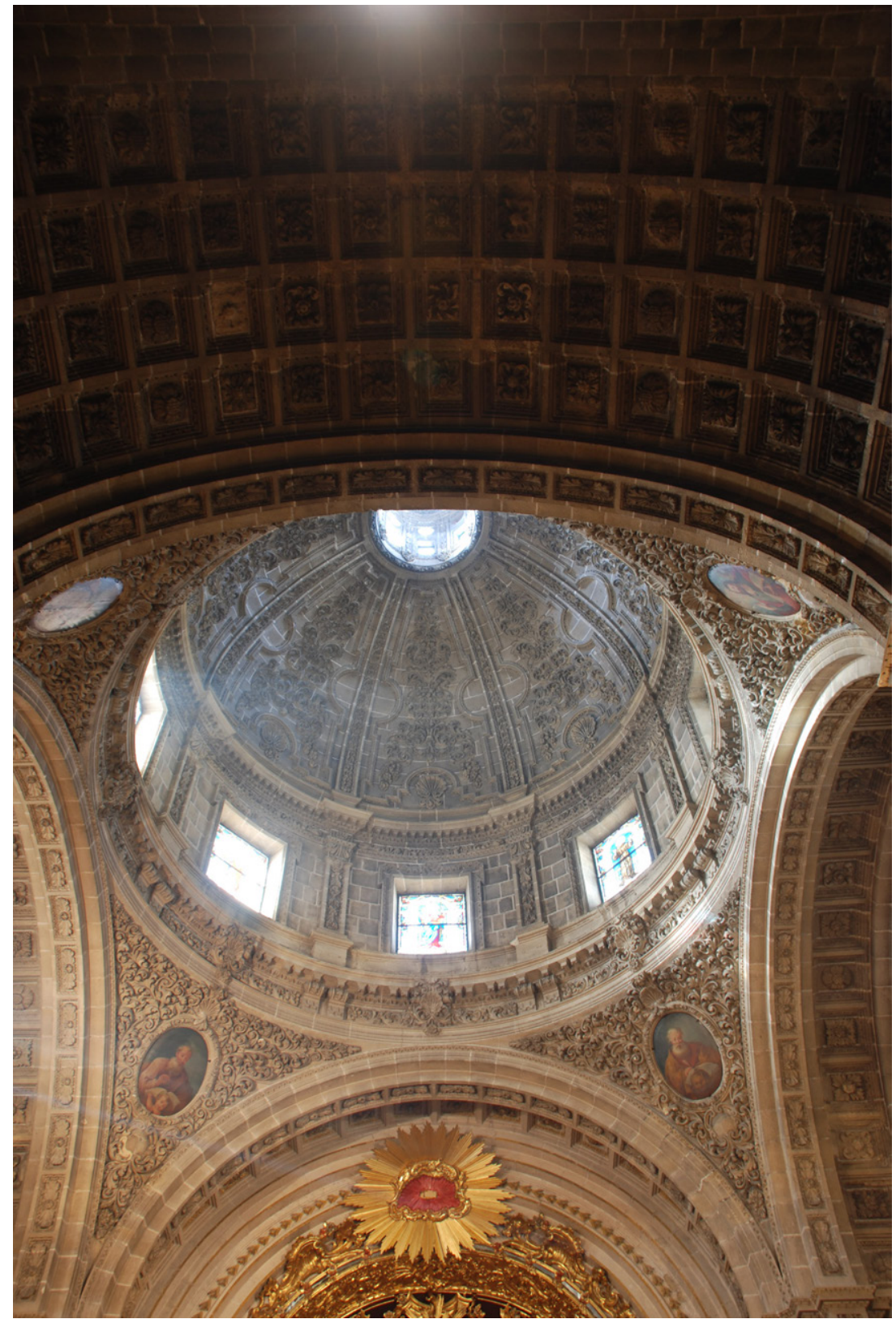

Figura 1. Interior del sagrario, primera mitad del siglo XVIII, parroquia de San Miguel, Jerez de la Frontera. 


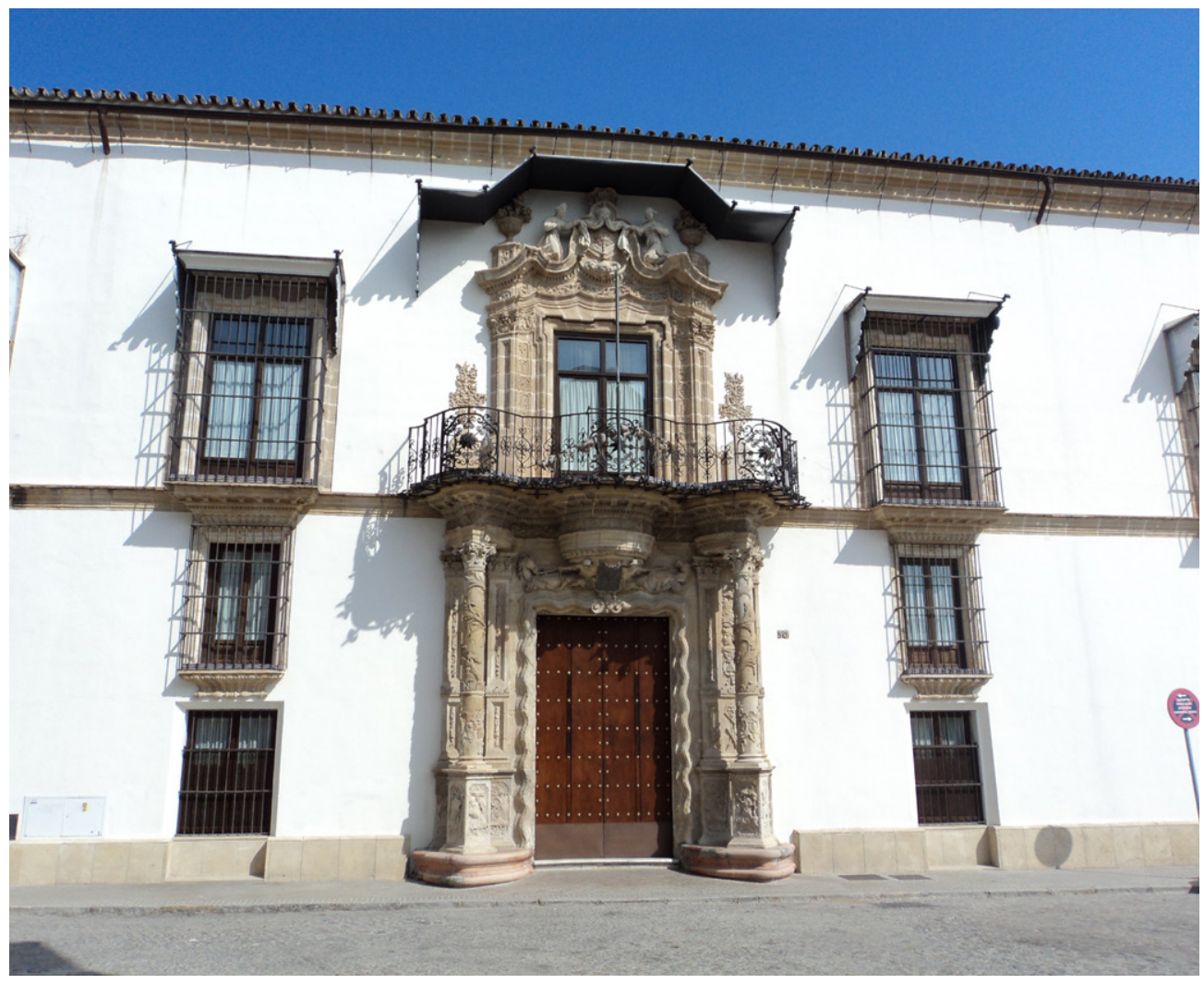

Figura 2. Juan de Vargas, Portada, 1777, palacio de Bertemati, hoy palacio Episcopal, Jerez de la Frontera. 


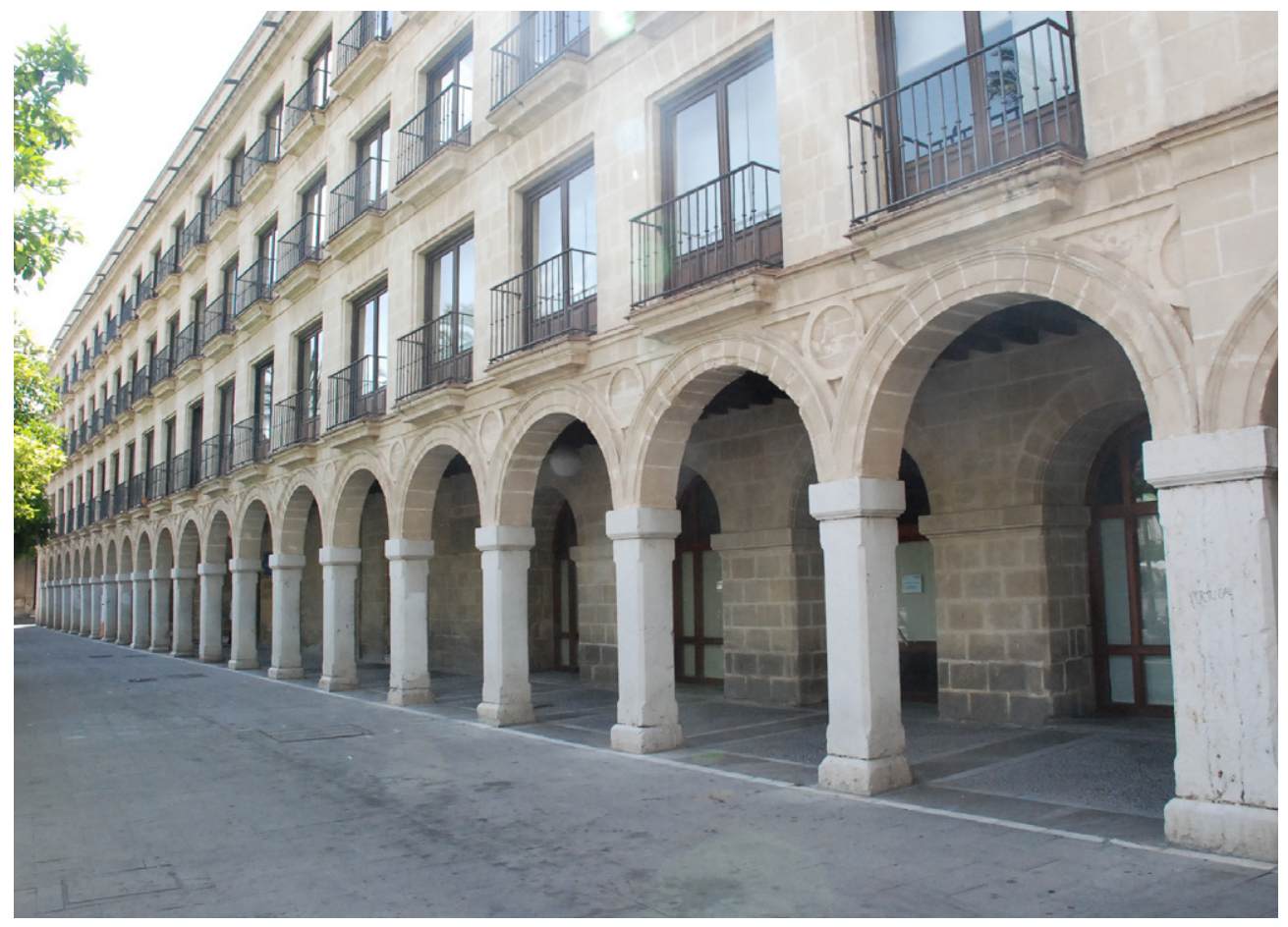

Figura 3. Soportales con pilares de piedra de Gigonza, reformas tras el incendio de 1794, antigua Alhóndiga y Panadería, Jerez de la Frontera. 


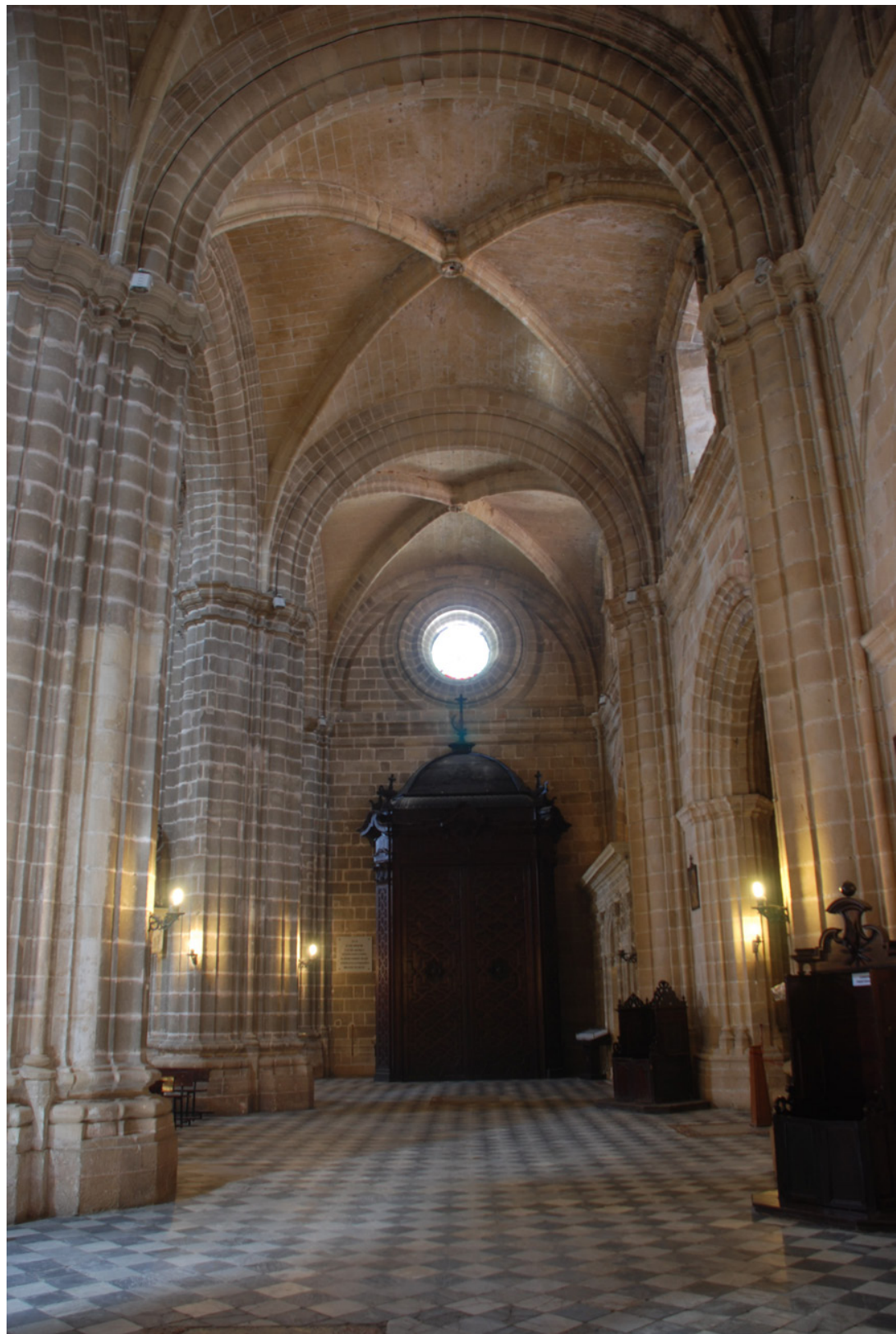

Figura 4. Bóvedas colaterales, primer tercio del siglo XVIII, catedral, Jerez de la Frontera. 


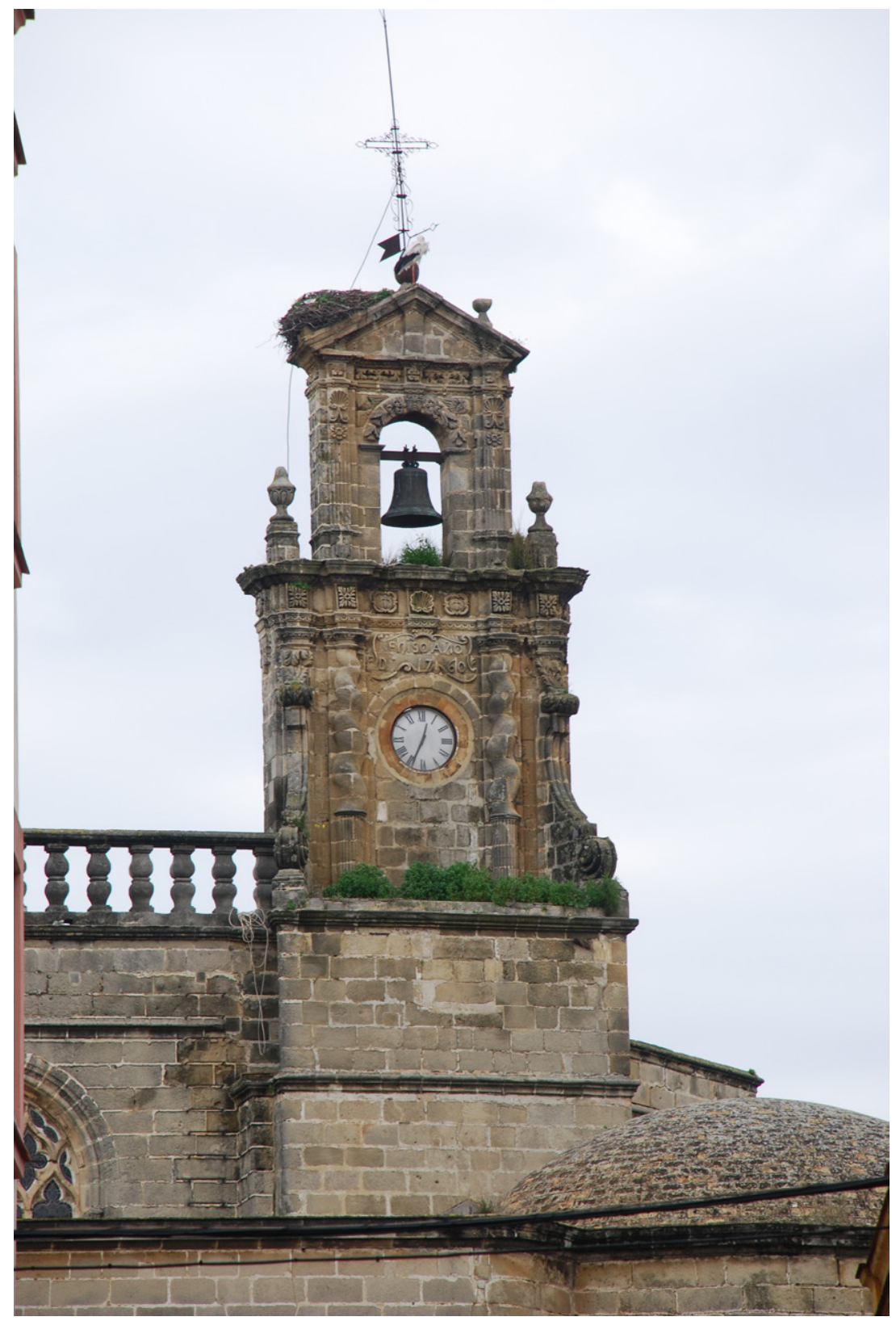

Figura 5. Juan de Vargas, Espadaña, 1760, parroquia de Santiago, Jerez de la Frontera. 